See discussions, stats, and author profiles for this publication at: https://www.researchgate.net/publication/317790049

\title{
A novel technique to estimate biological parameters in an epidemiology problem
}

Poster · June 2017

CITATIONS

0

2 authors:

Antone dos Santos Benedito

São Paulo State University

4 PUBLICATIONS O CITATIONS

SEE PROFILE

Some of the authors of this publication are also working on these related projects:

Project Fractional Calculus View project

Project Modelos matemáticos de crescimento tumoral com terapias View project
READS

34

SEE PROFILE 


\title{
A novel technique to estimate biological parame- ters in an epidemiology problem
}

\author{
Antone S. Benedito \& Fernando L. P. Santos \\ Institute of Biosciences of Botucatu, UNESP, Dept. of Biostatistics, Brazil
}

\section{Abstract}

In this work we describe a study of parameters estimation technique [1] to estimate a set of unknown biological parameters of a nonlinear dynamic model of dengue. We also explore a Levenberg-Marquardt (LM) algorithm to minimize the cost function $[2,3,4,5]$. A classical model describes the dynamics of dengue mosquitoes in water and winged phases, where the data are availables. The main interest is fit the model to the data taking into account the parameters estimated. Numerical simulation was performed to show the the robustness of $\mathbf{L M}$ in estimating parameters.

\section{Objectives}

Develop a new technique to estimate the biological parameters in a ODE model of dengue and fit the data of male and females mosquito populations.

\section{Model}

Let the state variables and the biological parameters in Tables (1) and (2) respectively. The ode system used in this work is given below, We define $\mathbf{X}(t)=[A(t), I(t), F(t), M(t)]$ representing the continuous solution vector of the system (1) at time $t$.

$$
\left\{\begin{array}{l}
\frac{d A}{d t}=\phi\left(1-\frac{A}{C}\right) F-\left(\gamma+\mu_{A}\right) A \\
\frac{d I}{d t}=r \gamma A-\left(\beta+\mu_{I}\right) I \\
\frac{d F}{d t}=\beta I-\mu_{F} F \\
\frac{d M}{d t}=(1-r) \gamma A-\mu_{M} M
\end{array}\right.
$$

Table 1: State variables at the time $t$

$A(t)$ aquatic phase (immature forms)

$I(t) \quad$ no-fertilized females (before mating)

$F(t)$ fertilized females (after mating)

$M(t)$ males insects (natural male)

Table 2: Parameters to the model (1)

\begin{tabular}{ll}
\hline Parameter & Description \\
\hline$\gamma$ & Ratio of transition to winged form \\
$\beta$ & The effective mating rate \\
$r$ & The proportions of females \\
$(1-r)$ & The proportions of males \\
$\mu_{A}$ & Aquatic phase mortality rate \\
$\mu_{I}$ & Unmating female mortality rate \\
$\mu_{F}$ & Mating fertilized mortality rate \\
$\mu_{M}$ & Male mortality rate \\
$\phi$ & Intrinsic oviposition rate \\
$C$ & Carrying capacity \\
\hline
\end{tabular}
Value [6] Unit

0.121 days

$0.7 \quad$ days $^{-1}$

0.5

0.5

0.0583 days $^{-1}$

0.0337 days $^{-1}$

0.0337 days $^{-1}$

0.06 days ${ }^{-1}$

$353-10 y s^{-1}$

$3 \quad$ mosquito $^{-1}$

\section{Cost function}

Let $i \in \mathbb{D}:=\{0, \cdots, N\}$, where $N$ is the maximmum data observed in $[0, T], T$ is the total experimental time.

Let $E=\left\{\mathbf{X}_{i o b s}\right\}$ : the data from the experimental observation, for $i=0, \cdots, N$.

Let $\mathbf{b}=\left[b_{i o b s}\right]$ : the vector of known parameters (observed data), $\forall i=1, \cdots, m$.

Let $\mathbf{p}=\left(p_{1}, \cdots, p_{n}\right)$, where $n$ is the number of parameters to be estimated.

Cost function: Let the cost function $W$ be defined as:

$$
W(\mathbf{p})=\frac{1}{2}\|w(\mathbf{p})\|^{2}=\frac{1}{2} \sum_{i=1}^{m} w_{i}(\mathbf{p})^{2}=\frac{1}{2} \sum_{i=1}^{m} \sum_{l=1}^{k}\left(\mathbf{X}_{i}^{l}(\mathbf{p}, \mathbf{b})-\mathbf{X}_{i o b s}^{l}\right)^{2}
$$

The main problem involving parameter estimation consists of:

Minimize $W$ : Determine $\mathbf{p}$ that minimizes the cost function $W$, subject to $p_{k} \geq 0, \forall k=1$

\section{Algorithms}

\subsection{Parameters Estimation}

Step 1 - Input the observed data;

Step 2 - Set initial parameter guess $\mathbf{p}^{0}=\left[p_{1}^{0}, \cdots, p_{n}^{0}\right]$ for $\mathbf{p}$;

Step 3 - Build a function to calculate $\mathrm{X}$ from a mathematical model;

Step 4 - Calculate the cost function $W$ from Eq. (2) :

Step 5 - Build a routine to minimize $W$;

Step 6 - Return p.

\subsection{Levenberg-Marquardt (LM)}

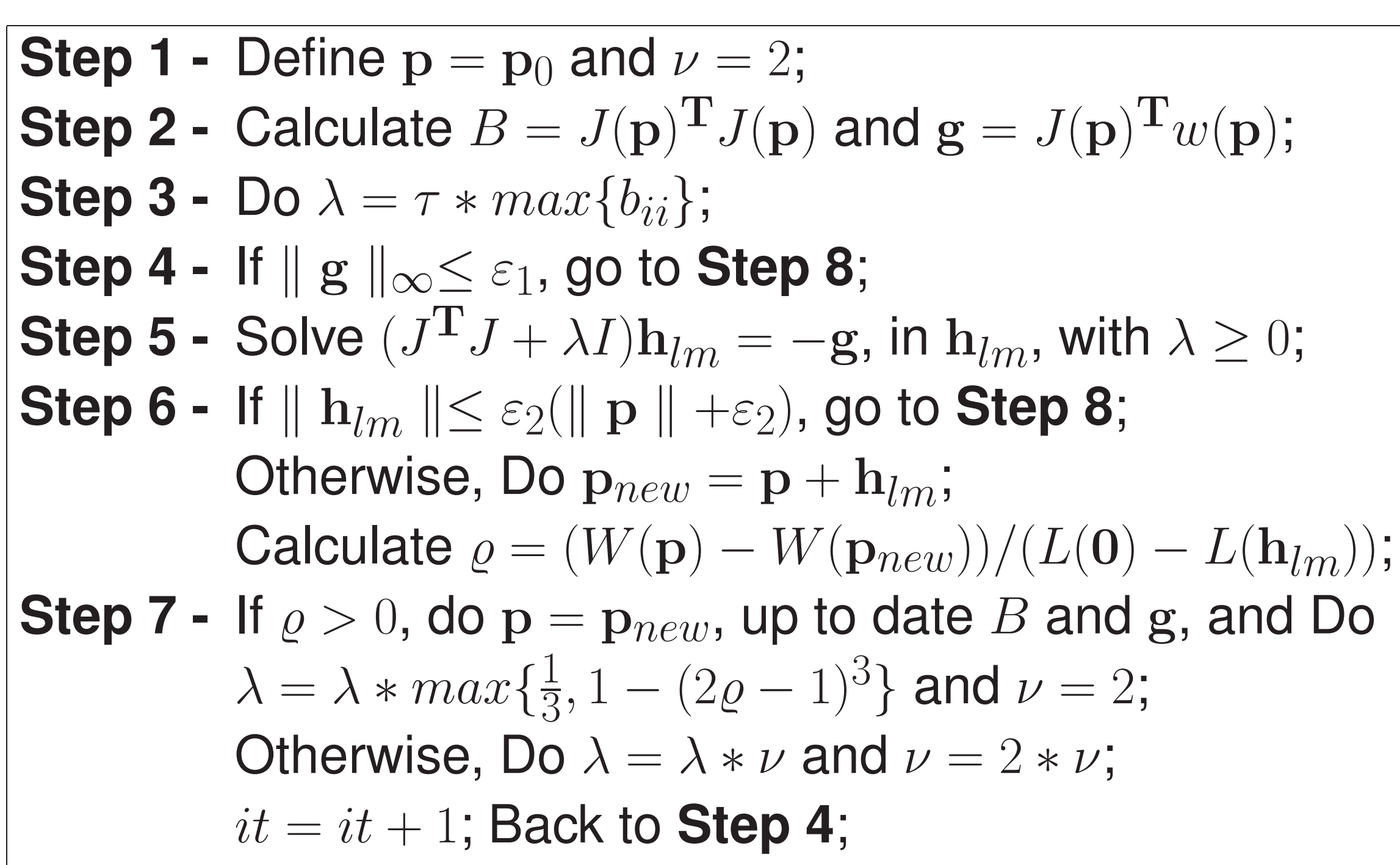

\section{Results}

We present here the results of the estimations.

1. Parameters to be estimated: $\mathbf{p}=\left(\mu_{F}, C, \mu_{M}\right)$;

2. Available data: $\mathbf{X}_{i o b s}=\left[A_{i o b s}, F_{i o b s}, M_{i o b s}\right]$;

3. Observed parameters: $\mathbf{b}=\left[\phi_{i o b s}\right]$;

4. Initial conditions $\left(A_{0}, F_{0}, M_{0}\right)=(0,100,30)$;

5. Parameters of simulations: Time-step $d t=1, \tau=10^{-3}$ and $\varepsilon_{1}=\varepsilon_{2}=10^{-8}$.

Table 3 shows the Comparisons $\mu_{F}$ and $\mu_{M}$ estimations at $25^{\circ} \mathrm{C}$ ). Figures (1) shown the numerical solution of the model 11 fitting the data of female and male mosquitoes, respectively. Table 4 shows Pearson correlation coefficient $\rho[9]$ values for cities $A$ and $B\left(30^{\circ} \mathrm{C}\right)$, indicating the strong linear correlation between the parameters estimated and the real data.

Table 3: Comparisons $\mu_{F}$ and $\mu_{M}$ estimations $\left(25^{\circ} \mathrm{C}\right)$

\begin{tabular}{cc|cccc}
\hline \multicolumn{2}{c}{ (Thomé, 2010) [8] } & \multicolumn{4}{c}{ Present work } \\
\hline$\mu_{F}$ & $\mu_{M}$ & $\mu_{F}$ - City A & $\mu_{F}$ - City B $\mu_{M}$ - City A $\mu_{M}$ - City B \\
\hline 0.0337 & 0.06 & 0.0249 & 0.0311 & 0.0666 & 0.0416
\end{tabular}
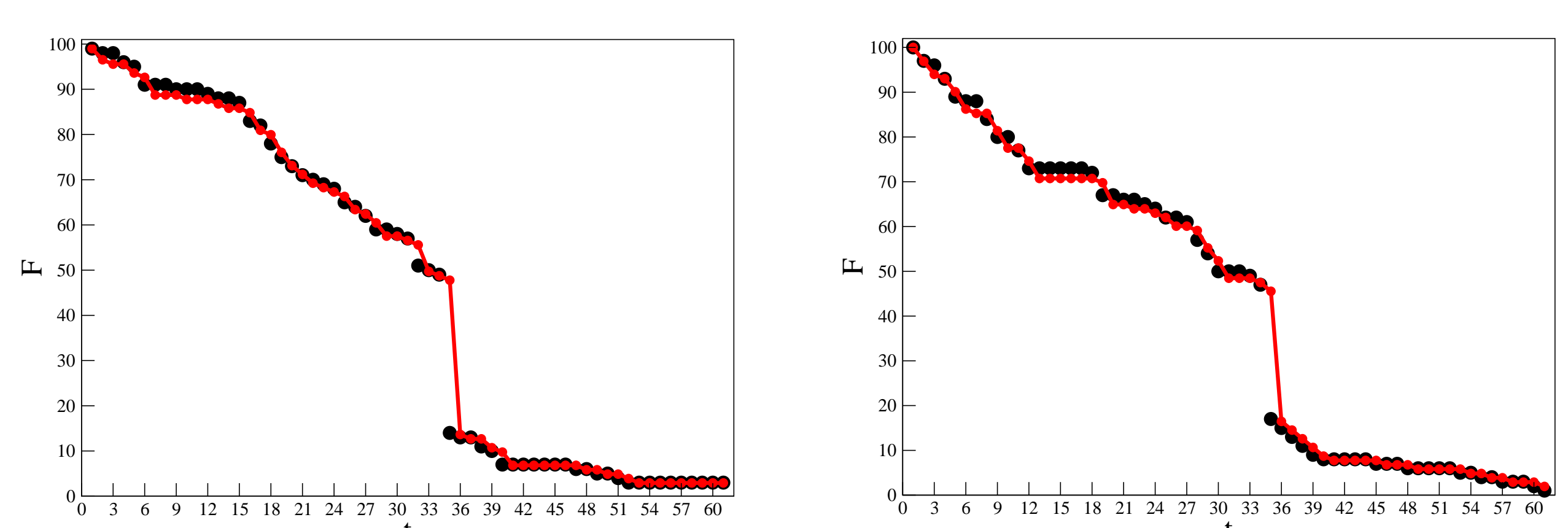

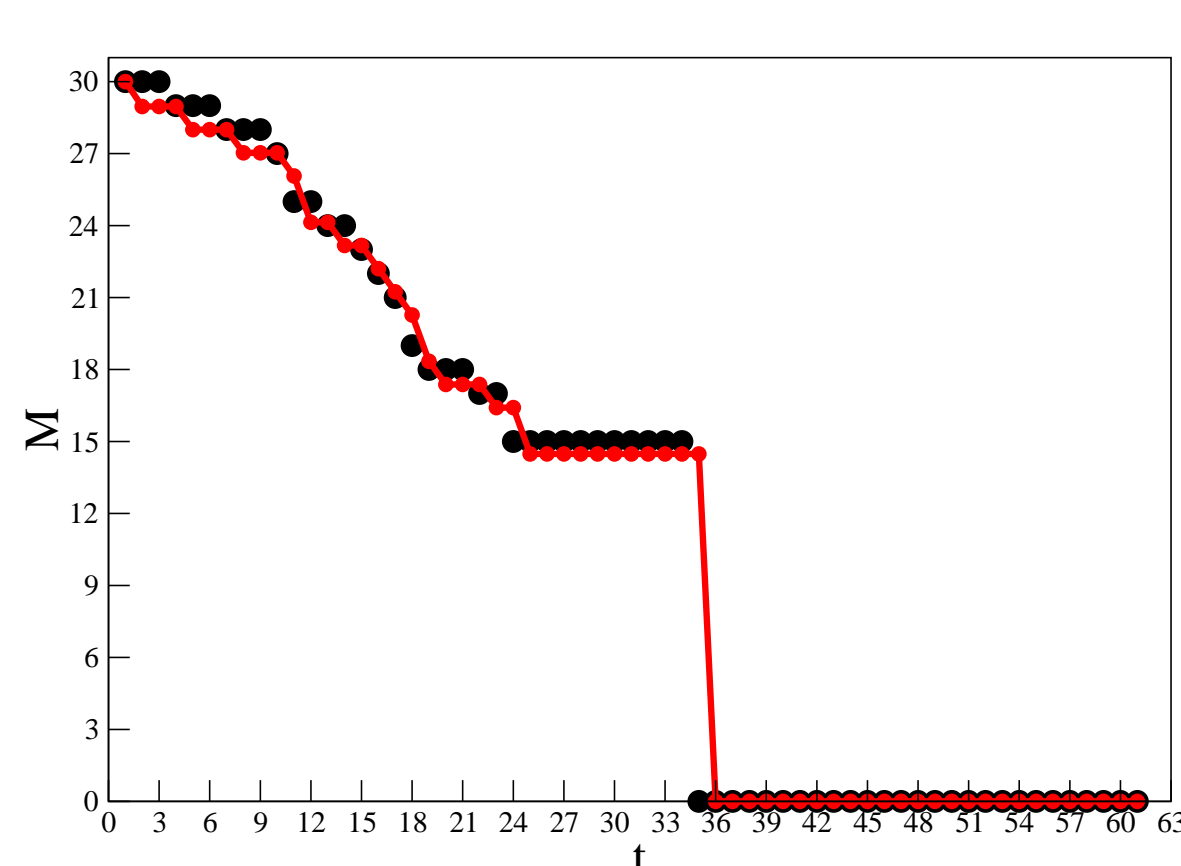

(c)

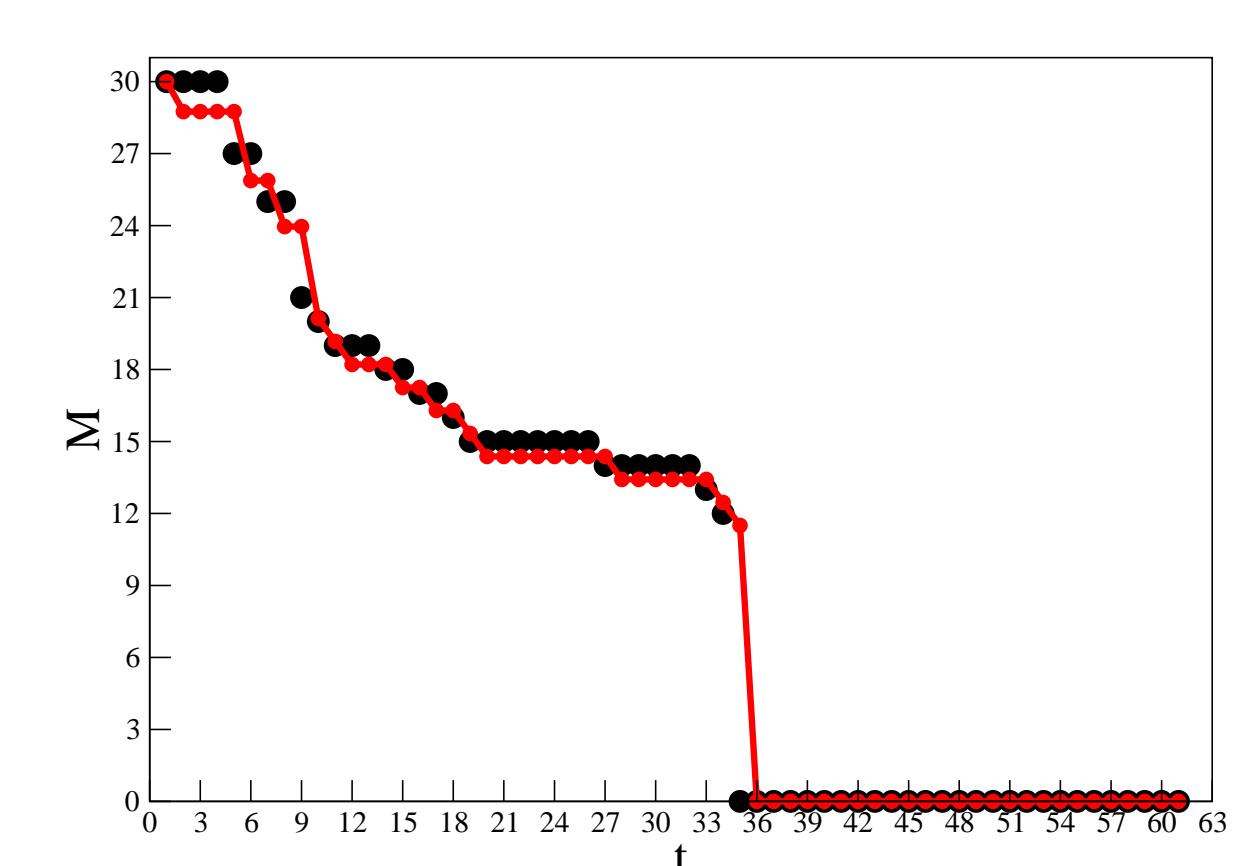

(d)
Figure 1: Dynamic of dengue mosquito populations $F(t)$ and $M(t)$ (from top to bottom) for the cities $\mathrm{A}$ (left) and $B$ (right) in $25^{\circ} \mathrm{C}$. Red line means predictions of the model and black dots depict the observed data of the aquatic phase, fertilized females and males of dengue mosquitoes.

$$
\text { Table 4: } \rho \text { values }\left(30^{\circ} \mathrm{C}\right) .
$$

City A 0.9999897260 .9984318250 .996482096

City B 0.9999767210 .9990487420 .995447591

\section{Conclusions}

1. The model was able to fit the dengue data in all tests performed;

2. The numerical solutions comparison with data show the robustness of the code to fit the dengue data available.

3. There are agreement between the estimated parameters and values from the literature;

4. The results show that this technique can be an important data analysis tool to be applied in dynamic population systems;

5. The novel technique presented here improved the application of the $L M$ algorithm as an optimization alternative to analyze the dengue disease with real data.

\section{Acknowledgments}

We thank to the brazilian agency CAPES for the master's scholarship provided and FAPESP (Proc. 2017/0970-06) for the financial support.

\section{References}

[1] T. Hogan, A. Shuvaev, D. Commenges, A. Yates, R. Callard, R. Thiebaut, B. Seddon: Clonally diverse $T$ cell homeostasis is maintained by a common program of cell-cycle control, J. Immunol, 190, 3985-3993, 2013.

[2] G. A. F. Seber, C. J. Wild Nonlinear Regression, Auckland, Wiley Interscience, 2003.

[3] J. E. M. M. da Silva Parameter estimation of compartmental models for positron emission tomography. Tesis (Título de Mestre), Escola Politécnica, USP, 2010.

[4] W. H. Press, S. A. Teukolsky, William T. Vetterling, Brian P. Flannery Numerical Recipes in C: The Art of Scientific Computing, Cambridge University Press, 1992.

[5] K. Madsen, H.B. Nielsen, O. Tingleff Methods for non-linear least square problems, Informatics and Mathematical Modelling Technical University of Denmark, 2004.

[6] H. M. Yang, M. L. G. Macoris, K. C. Galvani, M. T. M. Andrighetti, D. M. V. Wanderley Assesing the effects of temperature on the population of Aedes aegypti, the vector of dengue.

[7] H. O. Florentino, B. F. Bannawart, D. R. Cantane, F. L. P. Santos Multiobjective genetic algorithm applied to dengue control Mathematical Biosciences, 256, 1-17, 2014.

8] R. C. A. Thomé, H. M. Yang, L. Esteva: Optimal control of Aedes aegypti mosquitoes by the sterile insect technique and insecticide. Mathematical Biosciences. vol. 223, 1, 12-23 (2010).

[9] W. H. Press, S. A. Teukolsky, W. T. Vetterling, B. P. Flannery: Numerical Recipes in C: The Art of Scientific Computing, Cambridge University Press (1992) 